Les sources de l'Histoire des Mines : Nouveaux outils, Nouvelles approches

\title{
Préface à la revue des catalogues
}

\section{Martine Mille}

\section{(2) OpenEdition \\ 1 Journals}

Édition électronique

URL : http://journals.openedition.org/dht/731

DOI : $10.4000 /$ dht.731

ISSN : 1775-4194

Éditeur :

Centre d'histoire des techniques et de l'environnement du Cnam (CDHTE-Cnam), Société des élèves du CDHTE-Cnam

Édition imprimée

Date de publication : 1 décembre 2008

Pagination : 226

ISBN : 978-2-95-30779-2-6

ISSN : 0417-8726

\section{Référence électronique}

Martine Mille, «Préface à la revue des catalogues », Documents pour I'histoire des techniques [En ligne] 16 | $2^{\mathrm{e}}$ semestre 2008, mis en ligne le 05 octobre 2010, consulté le 24 septembre 2020. URL : http:// journals.openedition.org/dht/731; DOI : https://doi.org/10.4000/dht.731

Ce document a été généré automatiquement le 24 septembre 2020.

(c) Tous droits réservés 


\title{
Préface à la revue des catalogues
}

\author{
Martine Mille
}

1 Nous vous proposons dans cette livraison d'heureuses échappées belles: l'une en Angleterre, proposée par Liliane Pérez, avec le catalogue édité par A. P. Ledger et Roger Smith, Benjamin Vulliamy and the Derby porcelain manufactory, 1784-1795 (Derby, Derby museum \& art gallery) qui permet de cerner un grand réseau d'entrepreneurs anglais, entre Benjamin Vulliamy (1747-1811), horloger, orfèvre et décorateur de luxe installé avec son fils à Londres, et William Duesbury II (1763-1796), manufacturier de porcelaine du Derbyshire ; l'autre au Pays basque, présentée par Véronica Tello, avec le catalogue du Rialia Museo de la industria, Portugalete. Nous publions également, en relation avec l'exposition Pays'âges du Musée d'histoire naturelle de Lille, une analyse de la plaquette du plan relief des Hauts-Fourneaux de Denain, exposition universelle Paris 1889 (Site minier de Wallers-Aremberg, 29 septembre au 2 décembre 2007 «Savoir Fer, de charbon et d'acier "; Musée d'histoire naturelle de Lille, 16 décembre 2007 au 3 août 2008, "Pays'âges, au début il y avait la forêt »).

2 L'intérêt du catalogue Benjamin Vulliamy réside dans une synthèse facile d'accès sur les échanges entre ces entrepreneurs et sur leurs pratiques, assortie de l'édition commentée d'archives privées de la firme Duesbury de Derby entre 1784 et 1795 . Les éditeurs précisent certains ressorts des métiers du luxe, comme l'imitation des productions françaises: Vulliamy initie une dynamique d'amélioration et de perfectionnement à Derby en concurrence avec les prestigieuses productions sévriennes. La publication de la correspondance est réalisée avec intelligence et constitue l'un des atouts du catalogue. La mention d'un service de Sèvres, exposé lors d'un souper du Prince de Galles, donne lieu à une comparaison des fabrications entre la France et l'Angleterre. Les éditeurs réussissent de plus à identifier ce service de Derby, à partir des factures conservées dans les Royal Archives (Windsor Castle), dont ils fournissent le détail complet.

3 Les catalogues d'exposition Riala et Denain proposent quant à eux de saisir le développement de régions minières et sidérurgiques et de comprendre d'une part, la concentration des capitaux, soutenue par l'État, propulsant la région de Bizcaye au rang de premier centre sidérurgique d'Espagne au XIXe siècle et d'autre part, les atouts 
d'une région, l'Avesnois, aux sous-sols surexploités par l'activité sidérurgique au XIX siècle, marquée par l'ascension des maîtres de forges au sein de la Société Anonyme des Hauts-Fourneaux de Denain, grande entreprise sidérurgique du Nord. Denain nous propose également de suivre entre 2001 et 2006, la campagne de restauration de la maquette au final très peu exposée et depuis démontée et retournée dans les collections de l'ancien musée industriel de Lille.

On y apprend aussi les liens tissés au XIX ${ }^{\mathrm{e}}$ siècle entre Denain et la Biscaye, par des prises de participation au capital de sociétés espagnoles, au moment où les expositions universelles permettaient aux entreprises leader de s'imposer; la maquette à grande échelle (quatre mètres sur six, au $1 / 20^{\mathrm{e}}$ ), réalisée en 1882 à Denain, est présentée aux expositions d'Amsterdam (1883) et de Paris (1889). On perçoit enfin à travers la " Coleccion Altos Hornos de Vizcaya ", point d'orgue de la muséographie du Rialia Museo de la industria (Portugalete), l'importance des représentations de l'homme au travail dans l'industrie lourde au XIXe siècle. La muséographie n'est pas sans rappeler celle de la salle d'exposition de la maquette du plan relief des Hauts-Fourneaux de Denain, de «Pays'âges, au début il y avait la forêt » récemment proposée au Musée d'histoire naturelle de Lille, telle une réflexion muséale au-delà des Pyrénées, abolissant frontières et territoires, et réunie par ces représentations de l'homme, acteur et moteur de la prospérité sidérurgique au XIXe siècle.

\section{AUTEUR}

MARTINE MILLE

CDHTE-Cnam 